\title{
PERSOONLIKHEIDSKORRELATE VAN POSTTRAUMATIESE STRESVERSTEURING BY POLISIEBEAMPTES
}

\section{Sophia Henning}

M.A. (Sielkunde); Departement Sielkun ta, Randse Afrikaanse Universiteit

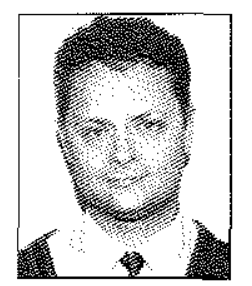

\section{Gideon P de Bruin}

M.A. (Voorligtingsielkunde); D. Litt. et Phil. (Sielkunde); N.H.O.D.

Senior Lektor; Departement Sielkunde, Randse Afrikaans Universiteit

\section{OPSOMMING}

Die doelstelling van die onderhawige studie was om die persoonlikheidskorrelate van posttraumatiese stresversteuring (PTSV) by polisiebeamptes te ondersoek. Hierdie studie is nodig geag aangesien (a) persoonlikheidstrekke 'n belangrike rol speel in 'n individu se kwesbaarheid vir die ontwikkeling van PTSV, en (b) polisiebeamptes as 'n hoë risikogroep vir die ontwikkeling van PTSV beskou word. Die PTSV onderhoudskedule is gebruik om 120 polisiebeamptes in twee groepe te verdeel, naamlik (1) die wat aan die kriteria vir 'n diagnose van PTSV voldoen $(n=41)$, en (2) die wat nie aan die kriteria voldoen nie $(n=79)$. Die tellings van die twee groepe vir die Comrey Persoonlikheidskale is vervolgens aan 'n diskriminantontleding onderwerp. Die diskriminante funksie het op statisties betekenisvolle wyse tussen die twee groepe onderskei. Die korrelasies tussen die Comrey Persoonlikheidskale en die diskriminante funksie het daarop gedui dat die PTSV groep meer neuroties, introversief, ordelik, wantrouend en emosioneel sensitief is.

\section{ABSTRACT}

The aim of this study was to investigate the personality correlates of post-traumatic stress disorder (PTSD) among police officers. This study was considered necessary because (a) personality traits play an important role in an individual's vulnerability for the development of PTSD, and (b) police officers are considered a high-risk group for the development of PTSD. The PTSD Interview Schedule was used to divide 120 police officers into two groups, namely (1) those complying with the criteria for a diagnosis of PTSD $(n=41)$, and (2) those not complying with the criteria $(n=79)$. The scores of the two groups for the Comrey Personality Scales were subsequently subjected to a discriminant analysis. The discriminant function significantly distinguished between the two groups. The correlations between the Comrey Personality Scales and the discriminant function revealed that the PTSD group showed greater neuroticism, introversion, orderliness, defensiveness and emotional sensitivity.

\section{PERSOONLIKHEIDSKORRELATE VAN POSTTRAUMATIESE STRESVER- STEURING BY POLISIEBEAMPTES}

Posttraumatiese stresversteuring (PTSV) word beskryf as ' $\mathrm{n}$ omvattende angsversteuring wat op blootstelling aan ' $\mathrm{n}$ buitengewone traumatiese ervaring mag volg (Shalev, Peri, Canetti \&
Schreiber, 1996:219). Die versteuring word gekenmerk deur terugkerende gedagtes en terugflitse rakende die traumatiese ervaring. Persone wat met PTSV gediagnoseer is, rapporteer ook dikwels nagmerries, emosionele afgestompdheid, verminderde responsiwiteit tot die eksterne wêreld en doelbewuste pogings om gedagtes of emosies rakende die traumatiese 
ervaring te vermy. Verdere simptome is onder meer hiperwaaksaamheid, oordrewe skrikresponse en outonomiese wekking wanneer die individu in aanraking kom met stimuli wat hom of haar aan die traumatiese gebeurtenis herinner (Joseph, Williams \& Yule, 1997).

Verskeie studies dui daarop dat die lewensbedreigende situasies waaraan polisiebeamptes uit die aard van hulle werksaamhede blootgestel word (en ook die antisipasie van sodanige situasies), hulle as "n groep kwesbaar maak vir die ontwikkeling van PTSV (Manolias \& Hyatt-Williams, 1993:392; Martin, McKean \& Veltkamp, 1986:98; Robinson, Sigman \& Wilson, 1997:835). Benewens die belewing van situasies waarin hulle eie lewens bedreig word, kom polisiebeamptes ook dikwels in aanraking met brutaliteit en gruweldade wat deur ander mense gepleeg word. Volgens Yehuda, Southwick en Giller (1992:504) se navorsing wat met veteraan-soldate van die Viëtnam oorlog gedoen is, mag blootstelling aan sodanige brutaliteit en gruweldade soms " $n$ beter voorspeller van PTSV wees as blootstelling aan situasies waarin die individu se lewe self bedreig word.

Dit blyk dat polisiebeamptes in Suid-Afrika $\mathrm{kwesbaar}$ is vir blootstelling aan lewensbedreigende situasies en die aanskouing van brutaliteit. SuidAfrika is ' $n$ land met " $n$ hoë geweldsmisdaadsyfer. Polisiebeamptes is ook dikwels die teiken van sodanige geweldsmisdade. Hierdie faktore dra daartoe by dat polisiebeamptes moontlik as " $n$ hoë risiko groep vir die ontwikkeling van PTSV beskou kan word (Nel \& Burgers, 1998:17).

Gulle, Tredoux en Foster (1998:129) tref ' $n$ onderskeid tussen inherente stres en organisatoriese stres in die Suid-Afrikaanse Polisiediens. Eersgenoemde het op die gevaarlike aard van polisiewerk betrekking en laasgenoemde het op stres wat deur die streng burokratiese aard van polisie-organisasies veroorsaak word, betrekking.
Ten opsigte van inherent stressore blyk dit dat blootstelling aan skietvoorvalle enstige gevolge vir polisiebeamptes kan inhou. Blau (1994) het in die V.S.A. aangetoon dat tot $80 \%$ van polisiebeamptes wat aan skietvoorvalle blootgestel is, die polisiediens daarna verlaat het. Martin, McKean en Veltkamp (1986:99) het aangetoon dat 26\% van die polisiebeamptes in hulle studie na afloop van 'n traumatiese gebeurtenis (waaronder skietvoorvalle) aan die kriteria vir PTSV voldoen het.

Alhoewel daar reeds baie navorsing oor die aard en etiologie van PTSV gedoen is, is daar min navorsing wat spesifiek op die verwantskap tussen die versteuring en basiese normale persoonlikheidstrekke fokus. Die doel van die onderhawige studie is om verdere lig op hierdie verwantskap te werp. Comrey (1995:2) se taksonomie van agt basiese persoonlikheidstrekke word as verwysingsraamwerk gebruik. Na ' $n$ omvattende program van faktoranalitiese navorsing, het Comrey (1970) agt basiese persoonlikheidstrekke geïdentifiseer. Hierdie persoonlikheidstrekke word deur die Comrey Persoonlikheidskale (Comrey, 1995) gemeet en staan bekend as (1) Vertroue versus Verdediging, (2) Ordelikheid versus Gebrek aan Kompulsiwiteit, (3) Sosiale Konformiteit versus Rebelsheid, (4) Aktiwiteit versus Gebrek aan Energie, (5) Emosionele Stabiliteit versus Neurotisisme, (6) Ekstroversie versus Introversie, (7) Emosionele Gehardheid versus Emosionele Sensitiwiteit en (8) Empatie versus Egosentrisme. Hierdie trekke is reeds in verskeie lande en in verskillende tale (waaronder Afrikaans) geïdentifiseer en gerepliseer (De Bruin, Nel \& Comrey, 1997:874). Die konstrukgeldigheid van die trekke is ook reeds deur gesamentlike faktorontledings van die Comrey Persoonlikheidskale en ander bekende persoonlikheidsmeetinstrumente, waaronder die Sestien Persoonlikheidsfaktorvraelys (De Bruin, 1998; Noller, Law \& Comrey, 1987:780), die Eysenck Persoonlikheidsinventaris (Noller, Law \& 
Comrey, 1987:780), en die NEOPersoonlikheidsinventaris (Caprara, Barbaranelli \& Comrey, 1995:198; Hahn \& Comrey, 1994:364) ondersteun.

Dit is relevant om die verwantskap tussen persoonlikheid en PTSV te ondersoek, aangesien dit blyk dat individuele verskille ten opsigte van persoonlikheid " $n$ rol kan speel by persone se kwesbaarheid vir die ontwikkeling van PTSV (Joseph, Williams, \& Yule, 1997). Hierbenewens is dit ook moontlik dat traumatiese ervarings tot veranderings in " $\mathrm{n}$ persoon se persoonlikheidseienskappe kan lei. Enkele studies waarin ' $n$ verband tussen basiese persoonlikheidstrekke en PTSV aangedui is, word vervolgens kortliks bespreek. In die eerste plek blyk verhoogde trekangs (of neurotisisme in Comrey se terminologie) ' $n$ positiewe verband met PTSV te hê. In 'n onlangse studie met Hollandse oorlogsveterane van die Tweede Wêreldoorlog, het dit geblyk dat veterane met PTSV, hoër tellings vir trekangs en depressie behaal het as veterane sonder PTSV (Hovens, Falger, Op den Velde, De Groen \& Van Duijn, 1994:284). Breslau, Davis, Andreski en Peterson (1991:221) het ook aangetoon dat neurotisisme ' $n$ risikofaktor vir die ontwikkeling van PTSV is. Benewens verhoogde neurotisisme, blyk dit dat introversie ' $n$ betekenisvolle voorspeller van stressimptome na blootstelling aan 'n stresvolle situasie, by polisiebeamptes is (Carlier, Lamberts \& Gersons, 1997:505).

Navorsing wat oor die verband tussen persoonlikheidsversteurings en PTSV gedoen is, kan ook meer lig werp op die verwantskap tussen persoonlikheidstrekke en PTSV, aangesien dit bekend is dat persoonlikheidsversteurings gekenmerk word deur ekstreme hoë of lae tellings ten opsigte van basiese persoonlikheidstrekke (Comrey, 1995:52). Dit blyk dat die volgende persoonlikheidsversteurings met PTSV kovarieer: (1) grenslynpersoonlikheidsversteuring, (2) obsessief-kompulsiewe persoonlikheids- versteuring, (3) vermydende persoonlikheidsversteuring en (4) paranoïede persoonlikheidsversteuring (Southwick, Yehuda \& Giller, 1993:1028). Die een basiese persoonlikheidstrek wat met al vier gemelde persoonlikheidsversteurings geassosiëer word, is neurotisisme. Hierbenewens word obsessief-kompulsiewe persoonlikheidsversteuring gekenmerk deur hoë ordelikheid (of konsensieusheid), vermydende persoonlikheidsversteuring deur hoë introversie, en paranö̈ede en grenslyn persoonlikheidsversteuring deur uitermatige wantroue in ander mense (Comrey, 1995:52). Die navorsing van Southwick et al. (1993) oor die verwantskap van PTSV met persoonlikheidsversteurings, suggereer dus dat die volgende persoonlikheidstrekke met PTSV verband mag hou: neurotisisme, ordelikheid, introversie, en wantroue.

Dit is egter moontlik dat van die oorblywende trekke in Comrey se taksonomie, naamlik sosiale konformiteit, aktiwiteit, emosionele gehardheid en empatie ook betekenisvolle korrelate van PTSV kan wees. In hierdie verband is dit veral emosionele gehardheid wat ' $\mathrm{n}$ betekenisvolle korrelaat van PTSV kan wees. Comrey (1995:39) wys daarop dat hierdie persoonlikheidstrek baie sterk met tradisionele manlike en vroulike stereotipes korreleer. Individue met hoë tellings vir die Emosionele Gehardheid versus Emosionele Sensitiwiteit skaal van die Comrey Persoonlikheidskale toon onder meer "n toleransie vir bloed, vulgêre taalgebruik en ongediertes. Hierbenewens huil hierdie individue nie maklik nie en hulle toon ook nie veel belangstelling in romantiese aspekte van die liefde nie (Comrey, 1995:3). Individue met hoë tellings is geneig om hulle emosies te onderdruk èn sal volgens Comrey baie huiwerig wees om hulp van ander mense aan te vra. Comrey (1995:39) rapporteer ook dat individue met hoë tellings vir hierdie skaal hulleself as imuun teen stres beskou. Dit is klaarblyklik dat manlike polisiebeamptes waarskynlik hoë tellings vir die Emosionele Gehardheid versus Emosionele 
Sensitiwiteitskaal behoort te behaal.

Die algemene hipotese wat in die onderhawige studie ondersoek is, is dat polisiebeamptes met PTSV verskil van polisiebeamptes sonder PTSV ten opsigte van die persoonlikheidstrekke in Comrey se taksonomie van persoonlikheidstrekke. Vervolgens word die navorsingsmetode wat in die studie gebruik is uiteengesit.

\section{METODE}

\section{Deelnemers}

Die deelnemers was 120 Afrikaanssprekende blanke, manlike onderoffisiere wat ten tye van die studie werksaam was in die Pretoria-gebied van die Suid-Afrikaanse Polisiediens. Al die deelnemers was funksionele polisiebeamptes wat aktiewe polisiëringsfunksies verrig het. Die deelnemers was verteenwoordigend van die volgende onderoffisiersrange: konstabels $(n=12)$, sersante $(n=78)$ en inspekteurs $(n=30)$. Die gemiddelde ouderdom van die deelnemers was 26,58 jaar en die gemiddelde aantal diensjare was 7,87. Die huwelikstatus van die deelnemers was as volg: ongetroud $(n=39)$, getroud $(n=74)$ en geskei $(n=$ 7).

\section{Prosedure}

Die insameling van die data het in 1997 plaasgevind. Toestemming is by stasiekommisarisse of verantwoordelike offisiere verkry om die data in te samel. Slegs persone wat gewillig was om skriftelike toestemming vir deelname aan die studie te gee, is as deelnemers gebruik. Die deelnemers is verseker dat die toetsresultate vertroulik hanteer sou word en dat dit slegs vir navorsingsdoeleindes gebruik sou word. Al die deelnemers is egter uitgenooi om insae te verkry in hulle toetsresultate.

\section{Meetinstrumente}

Die eerste instrument was die PTSV onderhoudskedule (Watson, Juba, Manifold, Kucala \& Anderson, 1991a:179). Hierdie instrument is gebruik om die deelnemers aan een van twee groepe toe te wys, naamlik 'n groep wat aan die kriteria van PTSV voldoen $(n=41)$ en 'n groep wat nie daaraan voldoen nie $(n=79)$. Die PTSV onderhoudskedule is gebaseer op die DSMIII-R kriteria vir PTSV.

Die PTSV onderhoudskedule bestaan uit (a) " $n$ afdeling waarin daar bepaal word of ' $n$ individu aan een of meer traumatiese situasies blootgestel is of nie en (b) 17 items wat betrekking het op PTSV simptome soos beskryf in die DSM-III-R. Vir elkeen van hierdie 17 items moet die respondent op ' $n$ sewe-punt skaal aandui hoe dikwels hy of sy die betrokke simptoom ervaar of nie. ' $n$ Faktorontleding van die simptome wat deur die PTSV onderhoudskedule geassesseer word, het vyf faktor opgelewer, naamlik: (1) Indringende gedagtes en hulle gevolge, (2) verhoogde wekking, (3) verarmde interpersoonlike verhoudings, (4) skuldgevoelens en nagmerries, en (5) geheue en konsentrasie (Watson, Kucala, Juba, Manifold \& Anderson, 1991b:212).

Die interne konsekwentheid betroubaarheid van die PTSV onderhoudskedule vir die onderhawige deelnemers kan as hoogs bevredigend beskou word $(\alpha=0,91)$. Watson et al. (1991a:185) rapporteer 'n toets-hertoets betroubaarheids-koëffisiënt van 0,95 vir die totaaltelling van die PTSV onderhoudskedule. Hieruit blyk dit dat betroubare tellings aan die hand van die PTSV onderhoudskedule verkry kan word. Ten opsigte van die samevallende geldigheid van die PTSV onderhoudskedule, toon dit korrelasies van tussen 0,79 en 0,94 met die Mississippi Scale for Combatrelated PTSD (Keane, Caddell \& Taylor, 1988:88), die Minnesota Multiphasic Personality Inventory PTSD Skaal (Keane, Malloy \& Fairbank, 
1984:888), en Robins en Helzer (1985) se Diagnostic Interview Schedule PTSD module (Watson, Plemel, DeMotts, Howard, Tuorila, Moog, Thomas \& Anderson, 1994:80). Hierdie korrelasies ondersteun die geldigheid van die PTSV onderhoudskedule.

Die Comrey Persoonlikheidskale (Comrey, 1995) is gebruik om metings van die polisiebeamptes ten opsigte van agt persoonlikheidstrekke te verkry. Benewens die agt persoonlikheidskale, het die Comrey Persoonlikheidskale ook 'n responssydigheidskaal en 'n geldigheidskaal. Vervolgens word ' $n$ kort beskrywing van elkeen van die agt persoonlikheidskale gegee.

Vertroue versus Verdediging: Individue wat ' $n$ hoë telling vir hierdie skaal behaal, beskou ander mense as vertrouenswaardig. Lae tellings dui op wantroue en die verwagting dat mense geneig is om misbruik te mak van ander mense.

Ordelikheid versus Gebrek aan Kompulsiwiteit:

Hoë tellings dui op hardwerkendheid, pligsgetrouheid, georganiseerdheid, netheid en stiptelikheid. Lae tellings dui op onverantwoordelikheid, sorgeloosheid, onnetheid en 'n onvermoë om stiptelik te wees.

Sosiale Konformiteit versus Rebelsheid: Hoë tellings dui op samewerking met persone in outoriteitsposisies en aanvaarding van gesag. Lae tellings dui op weerstand teen die sosiale sisteem en ' $n$ vyandige houding teenoor gesag.

Aktiwiteit versus Gebrek aan Energie: Persone met hoë tellings kan vir lang periodes werk, beskik oor stamina en is ambisieus. Persone met lae tellings beskik oor lae energievlakke en vind dit moeilik om alledaagse probleme die hoof te sien.

Emosionele stabiliteit versus Neurotisisme: Hoë tellings dui op emosionele stabiliteit. Lae tellings dui op 'n geneigdheid tot angstigheid, depressie, skuldgevoelens en gemoedskommelings.

Ekstroversie versus Introversie: Hoë tellings dui op 'n voorkeur vir sosiale interaksie. Lae tellings dui op ongemak in die teenwoordigheid van vreemdelinge en sosiale onttrekking.

Emosionele gehardheid versus Sensitiwiteit: Hoë tellings dui op eienskappe wat met die tradisionele manlike stereoptipe geassosieer word. Empatie versus Egosentrisme: Hoë tellings dui op simpatieke houdings jeens ander persone, behulpsaamheid en onselfsugtigheid. Lae tellings dui op onbesorgdheid oor die welstand van ander persone.

'n Afrikaanse vertaling van die Comrey Persoonlikheidskale is in die onderhawige studie gebruik (de Bruin, 1998). Die betroubaarheid van die Comrey Persoonlikheidskale kan as bevredigend beskou word. De Bruin (1998:91) rapporteer die volgende interne konsekwentheid betroubaarheidskoëffisiënte vir Afrikaanssprekendes: Vertroue versus Verdediging, 0,71; Ordelikheid versus Gebrek aan Kompulsiwiteit, 0,82; Sosiale Konformiteit versus Rebelsheid, 0,66; Aktiwiteit versus Gebrek aan Energie, 0,82; Emosionele Stabiliteit versus Neurotisisme, 0,83; Ekstroversie versus Introversie, 0,92; Gehardheid versus Sensitiwiteit, 0,82; en Empatie versus Egosentrisme, 0,89. Die geldigheid van die Comrey Persoonlikheidskale is reeds kortliks in die voorafgaande paragrawe bespreek.

\section{RESULTATE EN BESPREKING}

Op grond van die respondente se response vir die PTSV onderhoudskedule is hulle in twee groepe verdeel, naamlik (a) 'n groep wat aan die kriteria vir PTSV voldoen $(n=41)$ en (b) 'n groep wat nie aan die kriteria voldoen nie $(n=79)$. As daar in ag geneem word dat die voorkoms van PTSV in die algemene populasie tussen 1 en $2,6 \%$ is (Helzer, Robins \& McEvoy, 1987:1632), blyk dit dus dat "n betekenisvolle hoeveelheid van die polisiebeamptes in die onderhawige studie (34\%) aan die kriteria voldoen het. Hierdie hoë syfer kan moontlik aan die buitegewoon stresvolle aard van polisiëringstake toegeskryf word. Dit is egter ook moontlik dat 'n aantal polisiebeamptes juis 
vrywilliglik aan die studie deelgeneem het omdat hulle vermoed het dat hulle wel aan die kriteria sou voldoen.

'n Direkte diskriminantontleding is vervolgens uitgevoer ten einde vas te stel of die PTSV-groep en die nie-PTSV-groep in " $n$ meer veranderlike konteks ten opsigte van die Comrey Persoonlikheidskale verskil. Die gemiddeldes en standaardafwykings van die twee groepe vir die afsonderlike Comrey Persoonlikheidskale verskyn in Tabel 1.

Aangesien daar slegs twee groepe by die ontleding ingesluit is, kon slegs een kanoniese diskriminante funksie aan die hand van die Comrey Persoonlikheidskale gevorm word. Hierdie kanoniese diskriminante funksie slaag daarin om op ' $\mathrm{n}$ statisties beduidende wyse tussen die twee groepe te onderskei $\left(\Lambda=0,77 ; \chi^{2}=30,06\right.$; g.v. $=$ $10 ; p=0,001)$. Die waargenome kanoniese korrelasie van 0,48 dui daarop dat $23 \%$ van die tussengroepvariansie aan die hand van die diskriminante funksie verklaar kan word. Hieruit blyk dit dat die diskriminante funksie op ' $n$ statisties betekenisvolle en prakties betekenisvolle wyse tussen die twee groepe onderskei.

Tabel 1: Ge muddeldes en standaardafwykings vir die Comrey Persoonlikheidskale

\begin{tabular}{|c|c|c|c|c|c|c|c|}
\hline & \multicolumn{2}{|c|}{ PTST-Groep } & \multicolumn{2}{|c|}{ Nie-PTSU-groejy } & \multirow[b]{2}{*}{$z^{\prime}$} & \multirow[b]{2}{*}{$t_{0 \text { ba }}$} & \multirow[b]{2}{*}{$p$} \\
\hline & $M$ & s.a. & $M$ & s.a. & & & \\
\hline T & 76,66 & 15,49 & 82,32 & 9,55 & $-2,47$ & 0,22 & 0,015 \\
\hline 0 & 103,51 & 10,60 & 97,92 & 10,87 & 2,69 & 0,24 & 0,008 \\
\hline$c$ & 11,05 & 11,65 & 98,04 & 12,49 & 0,86 & 0,08 & 0,394 \\
\hline A & 103,37 & 14,82 & 105,32 & 13,59 & $-0,72$ & 0,07 & 0,471 \\
\hline$S$ & 96,93 & 15,92 & 103,84 & 13,14 & $-2,54$ & 0,23 & 0,012 \\
\hline $\mathrm{E}$ & 85,30 & 18,51 & 96,23 & 22,57 & 2,67 & 0,24 & 0,009 \\
\hline M & 87,71 & 12,79 & 92,46 & 13,13 & $-1,90$ & 0,17 & 0,001 \\
\hline F & 103,78 & 16,28 & 101,24 & $13 \times 15$ & 0,92 & 0,08 & 0,358 \\
\hline $\mathrm{R}$ & 55,07 & 9,22 & 54,89 & 9,66 & 0,10 & 0,01 & 0,910 \\
\hline 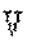 & 17,44 & 4,97 & 19,63 & 5,56 & $-2,12$ & 0,19 & 13,036 \\
\hline
\end{tabular}

Nota.' $\mathrm{g} w=118$. Die PTSV-groep bestagn uit 41 persone en die Hie-FTSW groep uit 39 pexone.

$T=$ Vertroue tersus Verdediging $\mathrm{O}=0$ rdelikhid versus Gebrek aan Konmulsiwiteit, $\mathrm{C}=$ Sosiale

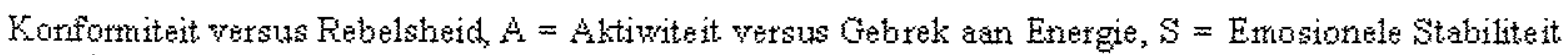

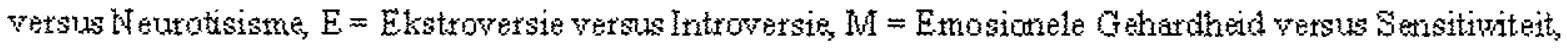

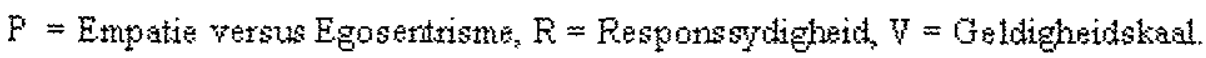


Ten einde die aard van die diskriminante funksie te begryp, word die gestandaardiseerde kanoniese diskriminante funksie-koëffisiënte en die korrelasies tussen die Comrey Persoonlikheidskale en die diskriminante funksie in Tabel 2 gelys. Die gestandaardiseerde kanoniese diskriminante funksie koëffisiënte verteenwoordig die gestandaardiseerde gewigte wat aan die Comrey Persoonlikheidskale toegeken is vir die berekening van die diskriminante funksie-tellings. Ten einde te begryp wat die aard van die verskille tussen die twee groepe is, is dit egter meer nuttig om die korrelasies tussen die Comrey Persoonlikheidskale en die diskriminante funksie te inspekteer. Hieruit blyk dit dat die belangrikste veranderlikes (in dalende rangorde) wat tot die onderskeid tussen die twee groepe bygedra het, die volgende was: Ordelikheid versus Gebrek aan Kompulsiwiteit ( $\mathrm{r}$ $=-0,45)$, Ekstroversie versus Introversie $(r=0,45)$, Emosionele Stabiliteit versus Neurotisisme ( $\mathrm{r}=$
Persoonlikheidskale, naamlik Sosiale Konformiteit versus Rebelsheid, Aktiwiteit versus Gebrek aan Energie, Empatie versus Egosentrisme en die responssydigheid-skaal het nie betekenisvolle bydraes tot die onderskeid van die twee groepe gelewer nie.

Hierdie resultate is in ooreenstemming met vorige studies wat op ' $\mathrm{n}$ verwantskap tussen PTSV en neurotisisme en introversie dui. Die resultate ondersteun ook die afleidings wat op grond van die verwantskap tussen PTSV met persoonlikheidsversteurings gemaak is, naamlik dat PTSV verband hou met neurotisisme, ordelikheid, introversie en wantroue.

Die waargenome verskille tussen die twee groepe dui op " $n$ betekenisvolle verband tussen PTSV en persoonlikheidstrekke by polisiebeamptes. Daar dien egter op gelet te word dat ' $n$ groot hoeveelheid

Tabel 2: Gestandaardisende kanonise diskriminante funksie koëffisiente en kontasies tussen die Comme Perso onlikheidskale er die düstininante fumbsie

\begin{tabular}{|c|c|c|}
\hline CPS-skale & 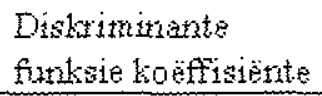 & $\begin{array}{l}\text { Kortelasies met } \\
\text { diskrimitrante funterie }\end{array}$ \\
\hline $\mathrm{T}$ & 0,48 & 0,41 \\
\hline 0 & $-0,45$ & 0,45 \\
\hline$c$ & $.0,24$ & $-0,14$ \\
\hline A & $-0,18$ & 0,12 \\
\hline 5 & 0,40 & 0,42 \\
\hline$E$ & 0,31 & 0,45 \\
\hline $\mathrm{M}$ & 0,27 & 0,32 \\
\hline P & 0,03 & 0,15 \\
\hline $\mathrm{V}$ & 0,53 & 0,35 \\
\hline P & $-0,15$ & $.0,02$ \\
\hline
\end{tabular}

$0,42)$, Vertroue versus Verdediging $(r=0,41)$, die Geldigheidskaal $(r=0,35)$ en Gehardheid versus Sensitiwiteit $(r=0,35)$.

Dit blyk dus dat polisiebeamptes wat aan die kriteria vir 'n diagnose van PTSV voldoen, (a) meer ordelik en kompulsief is, (b) meer introversief is, (c) meer neuroties is, (d) meer wantrouend is, (e) meer ongeldige profiele lewer en (f) meer emosioneel sensitief is. Die oorblywende Comrey variansie in PTSV $(67 \%)$ in die onderhawige studie nie deur persoonlikheidstrekke verklaar kon word nie. Hierdie variansie kan moontlik deur faktore soos diensjare, sosiale ondersteuning, aard van die stressore waaraan die polisiebeampte blootgestel is, finansiële status, metingsfoute en ander niebeheerbare foute verklaar word. Die huidige studie werp ook nie lig op die vraag of daar "n kousale verwantskap tussen PTSV en persoonlikheidstrekke is nie. Dit mag moeilik wees om 'n klinklare 
antwoord op hierdie vraag te verkry, aangesien die vraag sigself nie tot eksperimentele manipulering verleen nie.

Toekomstige studies van ' $n$ longitudinale aard mag help om verdere lig op die kousale verwantskap tussen persoonlikheidstrekke en PTSV te werp. In hierdie verband is " $n$ moontlike navorsingsontwerp om ' $n$ hele inname nuwe polisiebeamptes ten psigte van persoonlikheidstrekke met " $n$ instrument soos die Comrey Persoonlikheidskale te assesseer. $\mathrm{Na}$ ' $\mathrm{n}$ bepaalde tydsverloop (byvoorbeeld vyf jaar en dalk weer op 10 jaar) kan die verwantskap tussen die beamptes se aanvanklke tellings vir die persoonlikheidstrekke en PTSV status net soos in die onderhawige studie aan die hand van " $n$ diskriminantontleding ondersoek word "n Belangrike voorvereiste vir so " $\mathrm{n}$ studie is dat die aanvanklike persoonlikheidsmetings nie as " keuringsinstrument gebruik moet word nie, aangesien die keuring tot " $\mathrm{n}$ inperking van die variansie kan lei. Sodanige inperking van die variansie kan tot gevolg hê dat die verwantska tussen persoonlikheidstrekke en PTSV swakker voorkom as wat werklik die geval is. ' $n$ Verdere belangrike navorsingsterrein wat in die toekom ontgin kan word is die identifisering van faktore wat die weerbaarheid van polisiebeamptes (en ande persone wat dikwels aan intense stressor blootgestel word) teen die ontwikkeling van PTSV verhoog. In hierdie verband mag sosial veranderlikes (byvoorbeeld sosiale ondersteunin en sosio-ekonomiese status), sowel as sielkundige veranderlikes (byvoorbeeld ' $n$ positiew selfkonsep, optimisme en selfdoeltreffendheidsverwagtings) belangrike rolle speel.

\section{VERWYSINGS}

Blau, TH 1994: Psychological services for law enforcement. New York: Wiley.

Breslau, N; Davis, GC; Andreski, P \& Peterson, E 1991: Traumatic events and posttraumatic stress disorder in an urban population of young adults. Archives of General Psychiatry, 48:216-222.

Caprara, GV; Barbaranelli, C \& Comrey, AL 1995 Factor analysis of the NEO-PI Inventory and the Comrey Personality Scales in an Italian sample. Personality and Individual Differences, 18:193200

Carlier, IVE; Lamberts, RD \& Gersons, BPR 1997: Risk factors for posttraumatic stress symptomatology in police officers: A prospective analysis. Journal of Nervous and Mental Disease. 185:498-506.

Comrey, AL 1970: Manual of the Comrey Personality Scales. San Diego, CA: Edits.

Comrey, AL 1995: Manual and Handbook of Interpretations for the Comrey Personality Scales. San Diego, CA: Edits.

De Bruin, GP 1998: Die psigometriese eienskappe van die Comrey Personality Scales vir Afrikaanssprekendes [The psychometric properties of the Comrey Personality Scales for Afrikaans speakers]. Ongepubliseerde D.Litt. et Phil.proefskrif. Johannesburg: Randse Afrikaanse Universiteit.

De Bruin, GP; Nel, ZJ \& Comrey, AL 1997: Factor analysis of an Afrikaans translation of the Comrey Personality Scales. Psychological Reports, 81:867-876.

Gulle, G; Tredoux, C \& Foster, D 1998: Inherent and organisational stress in the SAPS: an empirica survey in the Western Cape. South African Journal of Psychology, 28:129-134.

Hahn, R \& Comrey, AL 1994: Factor analysis of the NEO-PI and the Comrey Personality Scales. Psychological Reports, 75:355-365. 
Helzer, JE; Robins, LN \& McEvoy, L 1987: Posstraumatic stress disorder in the general population: Findings from the Epidemiologic Catchment Area survey. New England Journal of Medicine, 317:1630-1634.

Hovens, JE; Falger, PRJ; Op den Velde, W; De Groen, JHM \& Van Duijn, H 1994: Posttraumatic stress disorder in male and female Dutch resistance veterans of World War II in relation to trait anxiety and depression. Psychological Reports. 74:275 285.

Joseph, S; Williams, R \& Yule, W 1997 Understanding post-traumatic stress: A psychosocial perspective on PTSD and treatment. Chichester: Wiley.

Keane, TM; Caddell, JM \& Taylor, KL 1988 Mississippi Scale for Combat-related Posttraumatic Stress Disorder: Three studies on reliability and validity. Journal of Consulting and Clinical Psychology, 56:85-90.

Keane, TM; Malloy, PC \& Fairbank, JA 1984 Empirical development of an MMPI subscale for the assessment of combat-related post-traumatic stress disorder. Journal of Consulting and Clinical Psychology, 52:888-891.

Manolias, MB \& Hyatt-Williams, A 1993: Effects of postshooting experiences on police authorize firearms officers in the United Kingdom. (In: JP Wilson \& B Raphael eds. International handbook of traumatic stress syndromes. New York: Plenum.)

Martin, CA; McKean, HE \& Veltkamp, LJ 1986: Posttraumatic stress disorder in police and working with victims: A pilot study. Journal of Police Science and Administration, 14:98-101.

Nel, J \& Burgers, T 1998: Stress and trauma in the work environment: The South African Police Service. Unisa Psychologia, 25:17-25.
Noller, P; Law, H \& Comrey, AL 1987: Cattell, Comrey and Eysenck personality factors compared: More evidence for the five robust factors? Journal of Personality and Social Psychology, 53:775782.

Robins, LN \& Helzer, JE 1985: Diagnostic Interview Schedule (DIS), Version IIIA. St. Louis, MO: Washington University School of Medicine, Department of Psychiatry.

Robinson, HM, Sigman, MR \& Wilson, JP 1997 : Duty-related stressors and PTSD symptoms in suburban police officers. Psychological Reports, 81:835-845.

Shalev, AY; Peri, T; Canetti, MA \& Schreiber, S 1996: Predictors of PTSD in injured trauma survivors: A prospective study. American Journal of Psychiatry, 153:219-225.

Southwick, SM; Yehuda, R \& Giller, EL 1993: Personality disorders in treatment seeking combat veterans with posttraumatic stress disorder. American Journal of Psychiatry, 150:1020-1030.

Watson, CG; Juba, MP; Manifold, V; Kucala, T \& Anderson, PED 1991a: The PTSD Interview: rationale, description, reliability, and concurrent validity of a DSM-III based technique. Journal of Clinical Psychology, 47:179-188.

Watson, CG; Kucala, T; Juba, MP; Manifold, V \& Anderson, PED 1991b: A factor analysis of the DSM-III post traumatic stress disorder criteria Journal of Clinical Psychology, 47:205-214

Watson, CG; Plemel, D; DeMotts, J; Howard, MT Tuorila, J; Moog, R; Thomas, D \& Anderson, D 1994: A comparison of four PTSD measures convergent validities in Vietnam veterans. Journal of Traumatic Stress, 7:75-82 
Yehuda, R; Southwick, SM \& Giller, EL 1992: Exposure to atrocities and severity of chronic posttraumatic stress disorder in Vietnam combat veterans. American Journal of Psychiatry, 148:499-504. 